\title{
CAMINHOS DE TRANSGRESSÃO: A HEROÍNA QUE OUSA E DESAFIA NA OBRA-PRIMA DE KATE CHOPIN
}

Deisi Luzia Zanatta

Rosemary Elza Finatti

Resumo: Kate Chopin se tornou uma importante escritora da literatura realista dos Estados Unidos, no século XIX, por abordar a temática de conscientização feminina em sua obra. O universo feminino de suas narrativas constitui-se de personagens que buscam liberdade e autoafirmação em meio à hostilidade da dominação masculina na cultura fin de siècle. O despertar (1899), a obra-prima da autora, escandalizou a sociedade sulista estadunidense e foi considerado por grande parte da crítica como um romance vulgar e imoral, por tratar de questões como a independência afetiva, financeira e sexual da protagonista Edna Pontellier, que percorre um caminho transgressor em busca da emancipação. Nesse sentido, o presente trabalho objetiva apresentar a trajetória de emancipação feminina da heroína, que rompe com o estereótipo de mulher ideal construído pela ideologia patriarcal, por meio de atitudes consideradas subversivas para a época. Para tanto, a análise será embasada pelos pressupostos teóricos de Virginia Wolf (1942) acerca da imagem do anjo do Lar, de Wendy Martin (1988) em relação às personagens femininas da obra, de Antônio Candido (1976), Edward Morgan Forster (2005) e Ruth Miguel (2016) sobre a personagem de ficção e de Gérard Genette (1972) a respeito do foco narrativo.

Palavras-chave: $O$ despertar. Kate Chopin. Edna Pontellier. Emancipação feminina.

Abstract: Kate Chopin became an important writer of realist literature in the United States in the 19th century by addressing the theme of female consciousness in her work. The female universe of her narratives is composed of characters who seek freedom and self-affirmation amidst the hostility of male domination in the fin de siècle culture. The Awakening (1899), the author's masterpiece, scandalized the American Southern society and was considered by most critics as a vulgar and immoral novel, for dealing with issues such as the affective, financial, 
and sexual independence of the protagonist Edna Pontellier, who goes through a transgressive path in search of emancipation. In this sense, this paper aims to present the trajectory of female emancipation of the heroine, who defies the stereotype of the ideal woman established by the patriarchal ideology, through attitudes considered subversive for the time. For this purpose, the analysis will be based on the theoretical assumptions of Virginia Wolf (1942) about the image of the Angel in the House, Wendy Martin (1988) in relation to the female characters in the work, Antonio Candido (1976), Edward Morgan Forster (2005) and Ruth Miguel (2016) about the fictional character and Gérard Genette (1972) regarding the narrative focus.

Keyword: The Awakening. Kate Chopin. Edna Pontellier. female emancipation.

\section{INTRODUÇÃO}

Kate Chopin (1850-1904) é uma das autoras mais renomadas da literatura realista do século XIX. Seu multiverso ficcional é composto por temas abrangentes e de natureza universal, retratando a vida por trás das máscaras sociais. Dentre as temáticas polêmicas como o preconceito racial, o divórcio e as dificuldades do relacionamento conjugal, a questão da mulher na sociedade em busca de emancipação e liberdade tornou-se o tema fulcral abordado pela autora em suas obras. Viúva precocemente e mãe de seis filhos, Chopin enfrentou muitas dificuldades para se tornar uma escritora aos 39 anos. Com coragem e ousadia, a autora buscou por um espaço em meio a tradição literária masculina, subvertendo, assim, os padrões literários conservadores da 
época e deixando uma marca indelével de sua atuação avant la lettre para o século XIX.

É notável que Kate Chopin tenha percorrido diversos gêneros literários e escrito mais de cem contos, cerca de cinquenta poemas, três romances, vários ensaios críticos, partituras musicais e traduções durante um período relativamente curto, entre os anos de 1889 e 1902, compondo, dessa forma, uma rica produção literária, tanto em termos quantitativos, como pela expressividade artística de seus textos, que a consagraram como uma exímia escritora. Dentre as obras mais importantes, $O$ despertar, a obra-prima de Kate Chopin, publicado em 1899 pela editora Herbert S. Stone \& Company, figura como um romance considerado o divisor de águas na vida da autora, uma vez que a recepção negativa por parte dos leitores e críticos da época trouxe consequências devastadoras para sua carreira literária.

O romance foi retirado das livrarias de Saint Louis, sua cidade natal, e Chopin teve sua coletânea de contos $A$ Vocation and a Voice rejeitada pela mesma editora, o que provocou o desinteresse de outras editoras por seus livros. Em 22 de agosto de 1904, a autora faleceu de hemorragia cerebral e seu legado literário foi esquecido por mais de duas décadas, até ser resgatado pelo biógrafo Daniel Rankin, 
em 1932. Apesar de todas as adversidades enfrentadas por Chopin após a publicação de $O$ despertar, a escritora recebeu o devido reconhecimento pela grandiosidade de sua escrita e foi consagrada como uma das grandes autoras da literatura realista norte-americana.

O presente artigo tem como proposta apresentar a trajetória de emancipação de Edna Pontellier, no que tange ao viés transgressor de suas atitudes para o contexto social do romance imerso na cultura finissecular. Nesse sentido, buscase analisar o universo feminino no que se refere à relação da protagonista com duas personagens femininas, Adèle Ratignolle, que representa a mulher-mãe e Mademoiselle Reisz, a mulher solteira e independente, bem como com as personagens masculinas Léonce Pontellier, Robert Lebrun e Alcée Arobin que personificam o casamento, o amor e a relação sexual extraconjugal respectivamente. A partir desta ligação, abordar atitudes consideradas como subversivas, de acordo com o patriarcalismo, que evidenciam o caminho transgressor da heroína de Chopin.

Com o intuito de atendermos ao objetivo proposto, este texto se organiza da seguinte maneira: a primeira seção apresenta o universo feminino no romance e a relação de Edna Pontellier com Adèle Ratignolle e Mademoiselle Reisz; 
na sequência, abordamos a relação da protagonista com o casamento, o amor e a paixão, entidades representadas por Léonce Pontellier, Robert Lebrun e Alcée Arobin. Para o desenvolvimento da análise do corpus realizamos um diálogo com os pressupostos teóricos de Virginia Wolf acerca da imagem do anjo do Lar; de Wendy Martin a respeito das personagens femininas da obra; de Antônio Candido (1976); Edward Morgan Forster (2005) e Ruth Miguel (2016) sobre a personagem de ficção; e de Gérard Genette (1972) a respeito do foco narrativo. Por fim, tecemos as considerações finais.

\section{O UNIVERSO FEMININO DO ROMANCE}

As personagens Adèle Ratignolle e Mademoiselle Reisz simbolizam duas imagens femininas extremas que acompanham a heroína em sua jornada em busca de autoafirmação e liberdade afetiva, financeira e sexual. A convivência com ambas as amigas permite a Edna encontrar possíveis identificações, visto que "a sua vida representa a tensão entre o código de dependência de Adèle Ratignolle e a política de ruptura de Madame Reisz"1 (MARTIN, 1988, p. 21, tradução nossa). Adèle e Edna se conhecem na colônia de veraneio de Grand Isle e, desde então, tornam-se amigas e confidentes. No entanto, a constante subserviência e o

1 "her life represents the tension between Adele Ratignolle's code of affiliation and the politics of separation of Madame Reisz". 
apagamento da individualidade da amiga provocam uma certa comoção na protagonista, visto que a vida de Adèle se limitava "ao cuidado dos filhos, à dedicação ao marido e ao cumprimento das obrigações sociais inerentes a uma mulher de posição social elevada" (ROSSI, 2006, p. 102).

No que diz respeito a Edna, o narrador do romance enuncia que:

Em resumo, a Sra. Pontellier não era do tipo maternal. As mulheres de tipo maternal pareciam predominar, naquele verão, em Grand Isle. Era fácil reconhecêlas, esvoaçando por ali com asas abertas e protetoras sempre que algum dano, real ou imaginário, ameaçava sua preciosa cria. Eram mulheres que idolatravam seus filhos, adoravam seus maridos, e valorizavam como um privilégio divino anularem-se como indivíduos e cultivarem asas qual anjos tutelares. (CHOPIN, 1994, p. 19)

A protagonista representa uma mulher que não dá atenção aos filhos. Adèle é o oposto de Edna, o lado da mulher-mãe que a personagem principal não consegue ser por completo, pois fica evidente sua paradoxal forma de amar: em alguns momentos os ama muito, querendo-os perto de si; em outros, sente-se livre, feliz e realizada por tê-los longe:

Gostava dos filhos de uma maneira impulsiva e irregular. Às vezes ela os apertava apaixonadamente em seu peito; 
outras vezes esquecia-os. No ano anterior eles tinham passado uma parte do verão com sua avó Pontellier, em Iberville. Sentindo-se segura a respeito de sua felicidade e bem-estar, não sentira sua falta exceto por alguma saudade ocasional intensa. A ausência deles era-lhe uma espécie de alívio, apesar de não admiti-lo, nem mesmo para si própria. Isto parecia libertá-la de uma responsabilidade que assumira cegamente e para a qual o Destino não a preparara. (CHOPIN, 1994, p. 32)

A citação mostra os pensamentos e sentimentos da protagonista em relação aos filhos. Assim, vale mencionar que Kate Chopin utiliza um narrador heterodiegético no romance. Sendo assim, esse narrador poderá adotar a técnica da onisciência seletiva múltipla como uma estratégia para trazer à tona o ponto de vista da personagem, como também projetar a subjetividade dela no discurso narrativo, através dos códigos de valores que regem e determinam as ações da personagem, filtrando o que ela pensa.

Essa oscilação entre os pensamentos das personagens e a voz narrativa pode destruir as marcas evidenciadas pelo discurso-narrador. Segundo Genette, "no discurso indireto livre, o narrador assume o discurso da personagem, ou, se preferir, a personagem fala pela voz do narrador, e as duas instâncias vêem-se então confundidas: no discurso imediato, 
o narrador dilui-se e a personagem substitui-se-Ihe" (1972, p. 172-173). Essa instância narrativa aparece muitas vezes na obra, fazendo com que os leitores notem as transformações ocorridas no monólogo da protagonista e como a direcionam na transgressão das normas patriarcais.

No ensaio "Profissões para mulheres" (1942), Virginia Woolf ilustra a submissão feminina através da imagem do Anjo do Lar, como representação do ideário patriarcal sobre as características fundamentais da mulher construída culturalmente como mãe e esposa dedicada, cuja identidade é moldada pela anulação de si mesma em prol do bem-estar dos filhos e do marido. Dentre tais atributos, a figurativização do Anjo do Lar revela que

ela era extremamente simpática.
Imensamente encantadora. Totalmente
altruísta. Excelente nas difíceis artes do
convívio familiar. Sacrificava-se todos os
dias. Se o almoço era frango, ela ficava
com o pé; se havia ar encanado, era ali
que ia se sentar - em suma, seu feitio era
nunca ter opinião ou vontade própria, e
preferia sempre concordar com as opiniões
e vontades dos outros. (WOOLF, 2012, p. 15)

No enredo, tal imagem é ilustrada pela presença das mulheres-mães na enseada de Grand Isle, em que Edna Pontellier passa as férias de verão com a família, sobretudo porque 
era muito fácil reconhecê-las, batendo suas asas estendidas, protetoras quando qualquer mal, real ou imaginário, ameaçava suas preciosas ninhadas. Elas eram mulheres que idolatravam seus filhos, veneravam seus maridos, e consideravam um santo privilégio anular-se como indivíduos e cultivar asas como anjos auxiliadores. (CHOPIN, 2002, p. 19)

Sob essa perspectiva, Madame Ratignolle é a personificação do Anjo do Lar woolfiniano, visto que a personagem possui as características de pleno devotamento e abnegação à maternidade e ao casamento, já que

Adèle encarna perfeitamente as definições sociais da feminilidade. O seu casamento é a expressão ideal da "fusão de dois seres humanos em um só". Preenchidos um pelo outro, os Ratignolles submergiram nos papéis que a sociedade prescreve para a intimidade; para a mulher, o de esposa e mãe; para o homem, o de provedor cuidadoso. Possuindo "toda a graça e encanto feminino", Adèle representa exatamente o que Edna não é, uma mulher-mãe, o tipo dominante em Grand Isle². (EWELL, 1986, p. 150, tradução nossa, grifos da autora)

Ao observar o predomínio da figura angelical feminina, a protagonista não consegue identificar-se com tais atitudes

2 Adèle perfectly embodies the social definitions of womanhood. Her marriage epitomizes the ideal "fusion of two human beings into one". Fulfilled by one another, the Ratignolles have submerged themselves in the roles society prescribes for intimacy; for women, that of wife and mother; for men, that of attentive provider. Possessing "every womanly grace and charm," Adèle represents exactly what Edna is not, a mother-woman, the dominant type at Grand Isle. 
marcadamente submissas, uma vez que seus anseios de autorrealização se opõem completamente aos papéis sociais de mãe e esposa, pautados pela cultura judaico-cristã. Em contrapartida, Edna admira a ousadia de Mademoiselle Reisz, uma pianista independente, solteira e avessa aos padrões femininos moldados pelos preceitos da sociedade do século XIX. Desse modo, a musicista inspira Edna a buscar um caminho de libertação das amarras patriarcais, tornando-se uma artista e alcançando, por sua vez, a autonomia por meio da venda de quadros. Nesse prisma,

enquanto Adele é uma "madona perfeita" que fala em nome dos valores e das leis da comunidade crioula, Mademoiselle Reisz é uma rebelde, intransigente e franca. Ela não tem paciência com regras sociais mesquinhas e viola as expectativas mais básicas da feminilidade ${ }^{3}$. (MARTIN, 1988, p. 46 , tradução nossa, grifos da autora)

Mademoiselle Reisz aparece no nono capítulo do romance durante uma reunião dançante na casa de verão da família Lebrun. Mademoiselle é uma mulher solteira e independente financeiramente, uma pianista, ou seja, atributos que o sistema patriarcal não considerava adequados para uma mulher. A forma como o narrador a

3 And whereas Adele is a "faultless madonna" who speaks for the values and laws of the Creole community, Mademoiselle Reisz is a renegade, self-assertive and outspoken. She has no patience with petty social rules and violates the most basic expectations of femininity. 
descreve evidencia essa assertiva: "Era uma mulherzinha desagradável, de meia idade, que se desentendia com quase todo mundo devido a um temperamento belicoso e a uma disposição de atropelar os direitos alheios" (CHOPIN, 1994, p. 40).

A influência dessa personagem na mudança pela qual a protagonista está passando é nítida: Mademoiselle sabe que Edna e Robert estão apaixonados a ponto de ser a confidente de ambos, além de despertar a protagonista para uma vida totalmente oposta às convenções patriarcais. Mademoiselle representa o lado que a protagonista pretende se tornar. É após regressar de uma visita à pianista que Edna resolve comunicar Léonce através de uma carta que decidiu se mudar da mansão Pontellier. A voz do narrador nos apresenta o seguinte:

Antes do jantar, naquela noite, Edna escreveu uma carta graciosa ao marido, contando-lhe sobre a intenção de se mudar para a casinha no mesmo quarteirão e de dar um jantar de despedida antes de sair, lamentando que ele não estivesse ali para compartilhálo, para colaborar no cardápio e ajudá-la a recepcionar os convidados. A carta ficou esplêndida e transbordava contentamento. (CHOPIN, 1994, p. 109)

Ao saber das intenções de sua esposa, Léonce the responde a carta com sentimento de reprovação, não aceitando as 
condições de Edna. Muito preocupado com o que as pessoas poderiam interpretar sobre a conduta financeira de seus negócios, no mesmo pacote do correio que continha a carta para Edna, Léonce enviara instruções a um arquiteto sobre a reforma da mansão Pontellier a ser executada durante sua ausência. Além disso, uma breve nota explicativa saíra no jornal diário, comunicando que o casal Pontellier faria uma viagem ao exterior e que a mansão passaria por uma reforma e assim "o Sr. Pontellier salvara as aparências" (CHOPIN, 1994, p. 124).

A troca de correspondência entre marido e esposa apresenta as máscaras da relação matrimonial, pois evidencia as ações de uma mulher decidida a romper com as regras do sistema patriarcal passando a se sustentar da venda da pintura de seus quadros e deixando de residir na residência onde viveu até então com Léonce e os filhos do casal.

De acordo com Forster (2005), as personagens redondas nos surpreendem de maneira convincente, ou seja, são aquelas que, de alguma forma, rompem com alguns estereótipos. É o caso da protagonista do romance. Edna representa uma mulher à frente de seu tempo, ela possibilita a identificação de mulheres que lutam pelos seus direitos e por um espaço na sociedade. Assim, por meio das 
ações dessa personagem, podemos relacionar os fatos que acontecem na narrativa com o mundo.

Ao retornarem da praia de Grand Isle, Léonce percebe que Edna está negligenciando seu papel como esposa e mãe, pois passou a não atender as necessidades dos filhos, Raoul e Etienne, especialmente quando um deles cai em convalescência, e ao abandonar as visitas das esposas e filhas de clientes abastados do comércio de Léonce nas terças-feiras à tarde. O diálogo entre o Sr. E a Sra. Pontellier apresenta uma relação conflituosa:

- Fora! - exclamou o marido com algo de genuína consternação genuína na voz, pousando a galheta de vinagre na mesa e olhando para Edna através dos óculos. - Ora, o que poderia tê-la levado a sair numa terçafeira? O que você tinha para fazer?

- Nada. Simplesmente fiquei com vontade de sair, e saí.

- Bem, espero que você tenha deixado alguma desculpa convincente - disse o marido, mais tranqüilizado, acrescentando uma pitada de pimenta Caiena à sopa.

- Não, não deixei desculpa nenhuma. Disse para o Joe dizer que eu havia saído, só isso.

- Mas minha querida, pensei tivesse compreendido, a essa altura, que as pessoas não fazem coisas assim; precisamos observar les convenances se quisermos acompanhar a procissão e não ficarmos para trás. Se decidiu sair de casa esta tarde, devia ter deixado alguma explicação adequada para sua ausência. 
- Esta sopa está realmente impossível; é estranho que aquela mulher ainda não tenha aprendido a fazer uma sopa decente [...] (CHOPIN, 1994, p. 71)

A conversa entre marido e mulher mostra que a protagonista está deixando de desempenhar o papel a ela destinado na sociedade e no lar para praticar algo que sua consciência deseja. A relevância da conversa que se estabelece entre Léonce e Edna mostra a estratégia de Kate Chopin em representar a repressão sofrida pela mulher ao tentar violar sua condição na esfera patriarcal.

Somando-se a isso, uma atitude relevante após a discussão ocorrida durante o jantar é a ação que Edna pratica contra a instituição do casamento, pisoteando sua aliança: "Em certo momento ela parou, e tirando a aliança de casamento, atirou-a no tapete. Quando a viu ali caída, pisoteou-a com o salto do sapato tentando esmagá-la. Mas o pequeno salto de sua botina não fez uma amassadura, uma marca sequer no anelzinho cintilante" (CHOPIN, 1994, p. 73-74).

Essa prática de Edna demonstra o descontentamento na esfera conjugal. Contudo, o sistema patriarcal se mantém resistente representado pela aliança intacta. Edna não se dá por vencida e analisa sua atitude de pisotear a aliança e quebrar um vaso, considerando esses atos como tolos de 
sua parte. A partir deste momento, as ações da protagonista em relação ao seu papel como dona do lar mudam, pois abandona completamente os dias de visitas nas terças-feiras em sua casa e não se importa mais com a supervisão dos afazeres domésticos, e com isso, a protagonista rompe com o paradigma da mulher do século XIX.

É no capítulo XXX do romance que Edna se torna efetivamente independente, se desfazendo das obrigações do casamento e da maternidade. Dessa forma, ela "decidira nunca novamente pertencer a alguém além de si mesma" (CHOPIN, 2002, p. 149), abandonando a mansão em que vivia com o marido e os filhos para morar sozinha em uma pequena casa nomeada por ela como casa de pombos. A mudança assinala que a heroína se desvencilha das frivolidades sociais e da vida de aparências que o casamento Ihe proporcionava, para mergulhar em sua subjetividade e realizar-se como sujeito de sua própria história, visto que "cada passo que ela dava em direção a se libertar das obrigações somava-se à sua força como indivíduo" (CHOPIN, 2002, p. 173).

A partir de então, Edna conquista a independência financeira, mantendo-se da venda de seus quadros e de suas economias. Para comemorar esse ato libertador, ela decide oferecer a um grupo seleto de amigos um jantar, evento 
que também celebra seu aniversário de vinte e nove anos. Para a festa, a protagonista não economiza nos adereços e na sua vestimenta luxuosa, nos enfeites requintados para ornamentar a mesa do jantar, nem no menu sofisticado oferecido aos convidados. Dessa forma, a heroína busca "um teto todo seu" (Woolf, 1983, p. 8), como preconiza Virginia Woolf a respeito da autonomia necessária para a mulher se profissionalizar, para se libertar das amarras do casamento, dedicando-se às próprias aspirações como artista e mulher.

Afrontando as normas preestabelecidas da cultura fin de siècle, a heroína apresenta à sociedade sua coragem e ousadia para viver conforme suas próprias regras. Sua atitude transgressora expressa que ela se torna uma "mulher régia, aquela que governa, que assiste, que é única" (CHOPIN, 2002, p. 164), evidenciando, por sua vez, o poder de decisão que ela adquire, avesso à condição feminina regida pelos ditames patriarcais. Sob esse viés, o jantar, "como observa Arobin, é um golpe de estado, a destruição do seu casamento, sobretudo um ato de agressão porque Léonce irá pagar as contas"4 (MARTIN, 1988, p. 51, tradução nossa). Ademais, a cena do jantar dialoga com a última ceia de Cristo, simbolizando, assim, uma afronta aos

4 "the dinner, as Arobin remarks, is a coup 'état, an overthrow of her marriage, all the more an act of aggression because Léonce will pay the bills". 
preceitos morais e religiosos, profanando os valores judaicocristãos. Assim como na Santa Ceia, Edna preside a mesa do jantar oferecendo um banquete aos doze convidados que, simbolicamente, alude à morte de sua condição como esposa submissa e o seu renascimento profano, aos olhos patriarcais, como uma mulher emancipada. Nesse sentido, a alusão bíblica

corresponde a uma espécie de "rito de passagem" em que Edna celebra a saída de um estado (a mulher que está unida ao marido, na mansão) para outro (a mulher que estará liberta, no chalé, dos laços matrimoniais. (SROCZYNSKI, 2009, p. 63, grifos da autora)

Desse modo, a transformação da protagonista "extrapola o rito de passagem e abarca os ritos de nascimento/ morte/ ressurreição" (SROCZYNSKI, 2009, p. 63), uma vez que, ao enfrentar as barreiras sociais impostas para uma mulher do século XIX, questionando os papéis sociais de mãe e esposa, ela adquire a "alma corajosa [...] a alma que ousa e desafia" (CHOPIN, 2002, p. 118), qualidade necessária para tornar-se uma artista e para sua autoafirmação.

Vale mencionar a importância que o jantar exerce no romance e no processo de emancipação de Edna Pontellier. Dentro da concepção judaico-cristã, o jantar representa 
um momento sagrado em que a família se reúne para confraternizar e celebrar. No decorrer da narrativa, ocorre uma ruptura do significado dessa convenção conforme preceitua a tradição religiosa e o poder patriarcal, pois, em algumas destas cenas, Edna também afronta as regras impostas pelo regime masculino.

A primeira ocorre quando durante um jantar, ela menciona ao esposo que não recebeu as visitas das terçasfeiras, porque esteve fora da Esplanada Street ocasionando um descontentamento em Léonce. A segunda se desenvolve na refeição noturna em que o Sr. Pontellier recebe seu sogro, o Coronel e convida Dr. Mandelet, médico e amigo da família para quem relatou a sua preocupação com as novas atitudes de Edna.

Neste jantar, Edna conta aos presentes uma de suas histórias cujo enredo trata sobre uma mulher que fugiu com seu amante numa piroga e nunca mais retornou. O relato proferido por Edna revela um tom apaixonado em sua voz, fazendo parecer verossímil aos ouvintes. Percebe-se que o assunto levantado pela personagem principal não é considerado adequado para uma mulher casada e mãe de dois filhos segundo as normas patriarcais, mas revela um desgosto com o casamento e um desejo íntimo de partir 
com Robert Lebrun, seu professor de natação por quem está apaixonada. Neste sentido, os jantares representam um ponto de partida para a tomada de decisões da protagonista, uma vez que ela pretende se desvencilhar da união familiar.

\section{ENTRE O CASAMENTO, O PRAZER E A PAIXÃO: A ESCOLHA POR SI MESMA}

O percurso do despertar da autorrealização de Edna é marcado pela presença masculina de Léonce Pontellier, o marido, Robert, seu amor platônico e Alcée Arobin, o amante. Léonce é um rico comerciante, é quem detém o poder financeiro dentro da esfera do lar. Edna parece ser mais um objeto, uma posse de seu marido que faz um comentário sobre o seu aspecto físico após esta tomar um banho de mar: "- Você está irreconhecível de tão queimada - acrescentou, olhando para a esposa como se olha para uma peça valiosa de propriedade pessoal que sofrera algum dano" (CHOPIN, 1994, p. 12). Outra passagem significativa da obra é quando Edna, após voltar da praia, pede que o esposo lhe devolva os anéis que ela havia solicitado que ele guardasse: "Estendeu silenciosamente uma mão em sua direção e ele, entendendo, tirou os anéis do bolso do colete e os deixou na palma de sua mão" (CHOPIN, 1994, p. 12).

O casamento revela a distância física e sentimental entre o casal, visto que 
Léonce Pontellier é uma personagem ausente, pois são relativamente esparsos os momentos em que aparece. Enquanto todos estão em Grand Isle, divertindo-se na praia ou conversando no salão dos Lebrun, Léonce prefere deixar esposa e filhos e ir jogar no cassino de um hotel. Em outro momento, já de volta à New Orleans, uma longa viagem o distancia da família, o que torna possível que se manifeste concretamente o despertar de Edna. Nos momentos em que está presente, o papel de Léonce torna-se claro: repreender os deslizes da esposa, ou seja, servir de porta-voz das convenções sociais - contraponto antagônico, portanto, da protagonista. (ROSSI, 2006, p. 98)

Já o personagem Robert Lebrun está sempre próximo da heroína durante as férias no Golfo do México. É ele que a ensina a nadar no mar, espaço simbólico da epifania do romance em que ela vislumbra novos caminhos para "nadar para longe, para onde nenhuma mulher havia nadado antes" (CHOPIN, 2002, p. 54), aludindo, dessa forma, ao despertar de sua subjetividade e do desejo de ser livre para fazer suas próprias escolhas. A voz narrativa mostra aos leitores a intimidade entre a protagonista e Robert no momento em que ambos estão sentados nos degraus da casa de veraneio:

[...] Robert e a Sra. Pontellier indolentemente sentados, trocando palavras, olhares e sorrisos ocasionais que indicavam algum estágio avançado de intimidade e 
camaradagem. Ele vivera à sombra dela durante o último mês. Ninguém parecia reparar. Muitos haviam previsto que Robert devotar-se-ia à Sra. Pontellier quando chegasse. Desde os quinze anos de idade, isto é, onze anos antes, a cada verão Robert se constituía no devotado acompanhante de alguma bela senhora ou senhorita, em Grand Isle. Algumas vezes era uma jovem, outras, uma viúva; com mais freqüência tratava-se porém de alguma mulher casada interessante. [...] A Sra. Pontellier gostava de ficar sentada olhando para seu belo acompanhante como olharia para uma Madona perfeita. (CHOPIN, 1994, p. 21-22)

O processo de libertação de Edna está totalmente ligado às vozes do mar que a encaminham para o aprendizado e para a descoberta do desejo, e Robert Lebrun estabelece uma espécie de ponte entre Edna e seu contato com o mar. Nesse sentido, Robert

chama Edna ao encontro do despertar propriamente dito e, além disso, a acompanha durante o caminho até a praia onde ela irá banhar-se e "perceber sua posição no universo". Robert é, assim, o guia do despertar, aquele que está no decorrer do caminho, mas não é o próprio caminho. Ele é o rio por sobre a ponte. (ROSSI, 2006, p. 144, grifos do autor)

Ao trilhar sua trajetória em busca de realização, a heroína envolve-se com Alcée Arobin, porém, sem ter com ele qualquer 
tipo de ligação emocional, mostrando, assim, a atitude subversiva diante dos valores morais e religiosos da época, que reprime qualquer forma de prazer da mulher, fora das restrições sociais das obrigações do casamento e da maternidade, e condena, veementemente, a infidelidade feminina.

O envolvimento entre Edna e Arobin inicia quando este a acompanha às corridas de cavalo. Mas, essa relação começa a se tornar constante na medida em que a protagonista passa a recebê-lo em visitas frequentes na mansão Pontellier, enquanto Léonce estava a negócios em Nova York. Por meio da descrição de Arobin, percebe-se o trânsito de sua figura pela vida mundana de Nova Orleans. Segundo o narrador(a):

Ele era uma figura familiar nas corridas, na ópera, nos clubes da moda. Exibia um perpétuo sorriso em seus olhos, que raramente deixavam de despertar um acolhimento equivalente em quem quer que os mirasse e ouvisse sua bem-humorada voz. Seus modos eram calmos e por vezes um pouco insolentes. Tinha boa aparência, um rosto agradável que não se sobrecarregava com pensamentos ou sentimentos profundos, e seu modo de trajar era o do homem mundano convencional. (CHOPIN, 1994, p. 99)

A heroína busca satisfazer seus desejos com o amante que "era absolutamente nada para ela. Ainda assim, sua presença, suas maneiras, [...] e, acima de tudo, o toque 
de seus lábios sobre suas mãos agiam como um narcótico sobre ela" (CHOPIN, 2002, p. 144). Assim, a relação com Alcée Arobin desencadeia em Edna uma série de sensações contraditórias, e através do discurso indireto livre é possível saber o que a protagonista sente:

Edna chorou um pouco naquela noite, depois que Arobin a deixou. Era apenas uma fase das multifacetadas emoções que a assaltavam. Manifestava-se nela uma dominadora sensação de irresponsabilidade. Havia o choque do inesperado e do insólito. Havia a recriminação do marido olhando-a a partir das coisas exteriores que a cercavam, que ele proporcionara para sua existência exterior. Havia a recriminação de Robert fazendo-se sentir através de um amor mais visceral, mais feroz, mais dominador e que despertara por ele em seu íntimo. Havia, sobretudo, a compreensão. Sentia como se uma névoa tivesse se levantado de seus olhos, permitindo-lhe ver e compreender o significado da vida, aquele monstro todo feito de beleza e brutalidade. Mas não havia vergonha ou remorso entre as sensações conflitantes que assaltavam-na. (CHOPIN, 1994, p. 111-112)

Edna afronta mais uma vez o poder patriarcal ao se envolver sexualmente com Arobin. A protagonista, ao se casar com Léonce, passa a ser um objeto de valor entre as posses do esposo. Ela o trai, caracterizando, assim, mais uma transgressão na mulher que está despertando. Além de causar 
prejuízo material ao marido por não se considerar mais uma propriedade dele, Edna fere a moral de Léonce em resposta a toda repressão sofrida ao longo do tempo em que esteve ao lado do Sr. Pontellier. Sob essa perspectiva, a emancipação sexual da heroína revela-se como uma afronta aos valores patriarcais.

Além disso, é interessante observar que, entre a estabilidade do casamento, a paixão platônica por Robert e os momentos de prazer com o amante, Edna prefere ser uma mulher livre, escolhendo a si mesma e todas as formas de plenitude que essa liberdade Ihe assegura. Isso se concretiza quando, ao retornar para sua casa após presenciar o parto de Adèle, a protagonista não encontra mais o seu amado Robert, mas apenas um bilhete deste dizendo o seguinte: "Eu a amo. Adeus... porque eu a amo" (CHOPIN, 1994, p. 147). A partir deste momento, acontece o desfecho da obra, momento em que Edna entra no mar em Grand Isle. Os pensamentos da protagonista surgem nas páginas do romance através do discurso indireto livre:

Pensou em Léonce e nas crianças. Faziam parte de sua vida, mas não deviam achar que podiam possuí-la de corpo e alma. Como Mademoiselle Reisz teria rido, zombado talvez, se soubesse! "E você se acha uma artista? Que pretensões, Madame! O artista deve possuir a alma corajosa que ousa e desafia. (CHOPIN, 1994, p. 151) 
O momento apresentado pela citação supracitada mostra a concretização do despertar de Edna Pontellier. A emancipação e a construção da autorrealização são transformações que possibilitaram à protagonista constituirse como sujeito.

Conforme Candido, "a compreensão que nos vem do romance, sendo estabelecida de uma vez por todas, é muito mais precisa do a que nos vem da existência. Daí podermos dizer que a personagem é mais lógica, embora não mais simples, do que o ser vivo" (CANDIDO, 1976, p. 59). Tal concepção só é possível, porque a construção da obra reúne elementos coerentes dentro do universo ficcional, ou seja, a personagem circula pelo enredo e interage com as demais figuras ficcionais, refletindo, de certa maneira, atitudes dos seres reais. Pode-se dizer que, assim, "unidos, enredo e personagem fazem parte de um todo consensual, no qual a personagem deve parecer tão perto do real quanto possível, deve ter vida, ser um ser vivo aproveitando os limites de sua própria realidade" (MIGUEL, s.p., 2016).

É isso que acontece com Edna, pois seus atos e percepções evidenciam as barreiras que muitas mulheres enfrentaram numa sociedade dominada pelo patriarcalismo. A interação com as demais personagens evidencia "os despertares" de 
Edna, permitindo-a se desvincular dos preceitos da égide masculina, transformando-se numa mulher emancipada.

\section{CONSIDERAÇÕES FINAIS}

Neste trabalho, apresentamos a trajetória de emancipação da Edna Pontellier, personagem principal do romance $O$ despertar (1899), que ao se dar conta de si como sujeito percorre um caminho transgressor por adotar atitudes consideradas inapropriadas pelo sistema patriarcal no século XIX. Para isso, examinamos o universo feminino por meio da relação da protagonista com duas personagens femininas, Adèle Ratignolle, que representa a mulher-mãe e Mademoiselle Reisz, a mulher solteira e independente, bem como com as personagens masculinas Léonce Pontellier, Robert Lebrun e Alcée Arobin que personificam o casamento, o amor e a relação sexual extraconjugal respectivamente.

Com o tema abordado no romance $O$ despertar, Kate Chopin desestabilizou a sociedade do sul dos Estados Unidos no século XIX, pois demonstrou a dominação e opressão nas relações de gênero, o discurso responsável pela sustentação concernente à posição do marido no meio familiar e social e a consequente tentativa de libertação feminina. A escritora representou a realidade de sua época através da literatura, recriando o universo em que vivia por meio do enredo de 
sua obra e das personagens ficcionais. Kate Chopin valeuse da literatura para despertar uma reflexão nas leitoras e nos leitores sobre a condição feminina, mostrando o que se esconde atrás das máscaras conjugais destinada à mulher: repressão e condição de inferioridade.

O presente artigo buscou contribuir para a fortuna crítica de Chopin no âmbito das pesquisas no Brasil, visto que a autora e a obra em questão são pouco conhecidas no espaço acadêmico. Como uma das precursoras da segunda onda do movimento feminista americano, Chopin mostrou a força de sua voz autoral, enfrentando desafios como mãe e escritora para se estabelecer na tradição literária masculina, com coragem e ousadia para traduzir em seus textos as vozes femininas silenciadas pela cultura patriarcal. A resistência empreendida em sua obra-prima como um romance de denúncia e, por essa razão, relegado ao esquecimento, evidencia que a ficção chopiniana revela-se como uma escrita atemporal, desde o século XIX até contemporaneidade, que se consagra como uma voz destoante e revolucionária na literatura de autoria feminina. 


\section{REFERÊNCIAS}

CANDIDO, Antonio. A personagem do romance. In: CANDIDO, Antonio et al. A personagem de ficção. 6. ed. São Paulo: Perspectiva, p. 51-80, 1976. CHOPIN, Kate. O despertar. Tradução de Celso Mauro Paciornik. São Paulo: Estação Liberdade, 1994.

CHOPIN, Kate. O despertar. Rio de Janeiro: Paz e Terra, 2002.

EWELL, Barbara C. Kate Chopin. New York: The Ungar Publishing Company, 1986.

FORSTER, Edward Morgan. Aspectos do romance. 4. ed. Tradução de Sérgio Alcides. São Paulo: Globo, 2005.

GENETTE, Gérard. Discurso da narrativa. Tradução de Fernando Cabral Martins. Lisboa: Veja, 1972.

MARTIN, Wendy (Ed.). New Essays on The Awakening. Cambridge (UK); New York: Cambridge University Press, 1988. (The American Novel). ROSSI, Aparecido Donizete. A desarticulação do universo patriarcal em The Awakening, de Kate Chopin. 2006. 195f. Dissertação (Mestrado em Estudos Literários). Faculdade de Ciências e Letras de Araraquara (FCL-Ar) - Universidade Estadual Paulista "Júlio de Mesquita Filho" (UNESP), Araraquara, 2006. Disponível em: https://repositorio.unesp. br/bitstream/handle/11449/91595/rossi ad me arafcl.pdf?sequ\%20 ence=1\&isAllowed=y. Acesso em: 16 jan. 2021.

SROCZYNSKI, Maria Eloisa Zanchet. A santa ceia e o banquete de Edna Pontellier: a intertextualidade entre o sagrado e o profano. Revista Trama, Cascavel, v. 5, n. 10, 2009. Disponível em: https://e-revista.unioeste.br/ index.php/trama/article/view/4408. Acesso em: 11 fev. 2021.

WOOLF, Virginia. Um teto todo seu. Tradução de Vera Ribeiro. 2. ed. Rio de Janeiro: Nova Fronteira, 1983.

WOOLF, Virginia. Profissões para mulheres e outros artigos feministas. Tradução de Denise Botmann. Porto Alegre: LP\&M, 2012. 


\section{Deisi Luzia Zanatta}

Doutora em Letras pela Universidade de Passo Fundo (UPF), em 2019. Atualmente, é professora tutora on-line do Núcleo de Educação à Distância da Católica de Santa Catarina - Centro Universitário, de Jaraguá do Sul-SC desenvolvendo atividades de docência na graduação. Membro da The Kate Chopin International Society (KCIS), desde 2012. E-mail: deisil.zanatta@gmail.com Lattes: http://lattes.cnpq.br/8512863768673611 ORCID iD: http://orcid.org/0000-0001-7356-1499

\section{Rosemary Elza Finatti}

Doutoranda em Estudos Literários pelo Programa de Pós-graduação da Faculdade de Ciências e Letras de Araraquara (UNESP).

Tem experiência na área de Letras, com ênfase em Língua e Literatura Inglesa. Desenvolve pesquisas sobre a vida e obra de Kate Chopin, Estudos Literários e Feminismo.

E-mail: rosefinatti@gmail.com

Lattes: http://lattes.cnpq.br/6123124938862607

ORCID iD: http://orcid.org/0000-0002-0605-4013 